\title{
Reaching the Hard to Reach: Mobile Development Screening Van to the Rescue
}

\author{
Joannie Busillo-Aguayo*, Wendy Murawski and Ivor Weiner
}

\author{
California State University, Northridge, CA, USA
}

\begin{abstract}
Currently more than $15 \%$ of children have an emotional, behavioral, or developmental concern. In spite of recommendations by the American Academy of Pediatrics and the Centers for Disease Control and Prevention to conduct universal developmental surveillance and screening with children at 9, 18, and 24 months of age, fewer than $30 \%$ of children under 6 years of age ever receive a developmental screening. Children in low-income and diverse communities are even less likely to be screened by a medical provider and/or referred for further diagnostic evaluation when predictive concerns are identified. As part of a cross-agency collaborative effort involving a family resource center, a child care resource and referral agency, a regional center for developmental disabilities, and a master's degree program in early childhood education, the Mobile Developmental Screening Van Project conducted outreach to provide free developmental screening with families of children 0-8 years of age in diverse and low-income communities within the greater Los Angeles County. Using the Parent Evaluation of Developmental Status (PEDS) screening tool, 94 children were screened over the course of 6 months, with $33 \%$ showing 2 or more predictive concerns that resulted in referrals for further diagnostic evaluation. The feasibility of reaching families in hard to reach communities using a mobile screening van, as well as study limitations and recommendations for next steps, are discussed.
\end{abstract}

Keywords: Developmental screenings, low-income, mobile screening, early childhood, community collaboration.

\section{INTRODUCTION/BACKGROUND}

Decades of research in neuroscience point to the conclusion that early brain architecture is influenced by the interplay between genetics, environment, and experiences during the first few years of life [1]. Furthermore, the neural circuitry developed during these early years forms the foundation for skills essential for success in life, such as higher-level critical thinking, problem-solving, and social and emotional competencies (e.g., self-regulation, motivation, empathy, compassion, and perseverance) [2]. Numerous longitudinal studies of children who were atrisk and disadvantaged demonstrate that when young children participate in high quality, comprehensive early intervention prior to reaching kindergarten, they are more likely to achieve long-term positive benefits in academic, social, and emotional skills [3]. Children with autism spectrum disorders in particular have a much better prognosis when they begin evidence-based early intervention during the first two years of life [4]. Furthermore, these gains continue to grow in value and benefit children and society throughout the child's lifespan. Accordingly, several American Nobel Prize winning economists argue that intervention for developmental, behavioral, social, or emotional challenges will yield the greatest social and economic returns - when it is provided during early childhood [5]. Simply put, the "early years matter" [6].

*Address correspondence to this author at the Department of Educational Psychology \& Counseling, Michael D. Eisner College of Education, California State University Northridge, 18111 Nordhoff Street, Northridge, CA 913308265, USA; Tel: 818-677-5725; E-mail: jaguayo@csun.edu

E-ISSN: 2292-2598/15
We have seen an alarmingly rapid rise in the number of children who experience some form of a developmental delay/disability, learning difficulty, or behavioral challenge over the past 20 years [7]. According to the Centers for Disease Control and Prevention (CDC), 1 in 68 children have an autism spectrum disorder and $15 \%$ to $17 \%$ have an emotional, behavioral, or developmental concern [7]. Of great concern is that fewer than $30 \%$ of children under 6 years of age ever receive a developmental screening [8] - and only $60 \%$ of these children screened receive a referral for further diagnostic evaluation and/or early intervention services when warranted [9]. Furthermore, in spite of being able to reliably diagnose autism spectrum disorder before 2 years of age when intervention is most effective, the average age of diagnosis for autism is between 4 and 5 years of age [10]. Consequently, fewer than $3 \%$ of children younger than 3 years of age and $5 \%$ of preschool-aged children receive early intervention, though research suggests that $13 \%$ would be eligible if identified [11].

There is an even greater disparity in the screening rates of those children and families hardest to reach, namely low-income, Hispanic, or African American children [12,13]. Children of color or those who live in low-income households are $50 \%$ less likely to be screened using a valid and reliable screening protocol than Caucasian or Asian children or those who are affluent [14]. The failure to screen, identify, refer, and receive early intervention services is rooted in many factors such as socioeconomic and cultural barriers (e.g., lack of transportation, difficulty navigating the 
maze of medical, educational or social services, or language and cultural barriers) [15,16]. Unfortunately, socioeconomic disadvantage and cultural and /or language barriers are strong risk factors associated with developmental disabilities [17].

There can be many reasons why young children may be at risk for poor developmental outcomes. Young children from low-income and disadvantaged environments are especially at risk for developmental, learning, or behavioral challenges as they are also exposed to the added stressors that often go hand in hand with economic disadvantage, such as parental stress, inadequate nutrition, poor medical care, or lack of access to high quality early learning experiences [3]. Numerous studies have documented that exposure to chronic stress beginning in early childhood has several potential long-term adverse effects on children's developmental, behavioral, social and emotional, health and well-being [18]. According to the National Scientific Council on the Developing Child Report [19], children who have been exposed to 6 or more chronic environmental stressors (e.g., inadequate parenting, minority status, single parent, poverty, low-caregiver education, or parental mental health disorders) are 90$100 \%$ more likely to experience cognitive, language or emotional delays. Thus, children with both developmental challenges and environmental stressors are at even greater risk for poor developmental outcomes, making it even more imperative to identify these children as early as possible.

As a result of the increased understanding of neuroscience and early brain development, the rapid rise in the number of children exhibiting developmental challenges, and the dismal failure to identify developmental challenges early, the American Academy of Pediatrics [20] and the CDC [7] recommend universal developmental surveillance. Universal developmental surveillance is designed to assess developmental and behavioral risks and determine if further diagnostic evaluation and/or referral for early intervention services are warranted for all children in the first five years of life [21]. Additionally, in recognition of the urgency to address developmental delays as early as possible, many neuroscientists also suggest evaluation of infants at their one-year exam as a means to ensure children's access to early intervention when it can have the greatest impact [22]. Yet, as reported by Shattuck et al. [10], even though medical professionals can reliably identify children with autism spectrum disorder by 2 or 3 years of age, the median age of diagnosis is 5.7 years.
In spite of solid support for early universal routine surveillance and screening for developmental delays [23], some have argued against the necessity and feasibility of large-scale coordinated and comprehensive community-based screening efforts [24]. However, just as all children receive routine vision and hearing screening at well-child visits, it is posited that children are likewise screened for developmental delays in the first few years so that problems can be identified and treated early when intervention can be most effective [25].

Children aren't the only ones to pay the price for failure to identify their developmental needs early and to ensure access to appropriate supports. Significant economic costs arise from increased need for special education, poor academic performance, higher rates of later incarceration, and lower overall lifetime earnings [4]. Thus, there is a critical need for a comprehensive strategy to reach children who are most at risk for developmental, learning, or behavioral challenges, yet are the least likely to ever be identified and/or receive critical early intervention services.

Comparable to the issues identified above, urban communities located in Los Angeles County encounter similar challenges and barriers [13]. Historically, families access needed services through referrals by medical providers or educational programs; however, in spite of the increasing numbers of children with developmental, learning, behavioral challenges and/or autism spectrum disorders, many children have not been identified until after they reached kindergarten. This is particularly evident for children from low-income and culturally / ethnically diverse communities. Similar to findings of other studies, families face many barriers in accessing early developmental screening for their children, such as lack of access to a stable medical care provider, lack of transportation, limited English speaking skills, or lack of knowledge about the availability of such services $[15,16]$.

In light of these findings, how can we effectively screen and refer the hardest to reach children living in urban communities within Los Angeles County who may need essential early intervention services? One successful approach utilized in Los Angeles County to improve identification of children from low-income and potential high-risk for developmental disabilities was the 2-1-1 LA Project, which conducted developmental screenings via phone interviews with families who had called in for a variety of health and social supports and services [13]. As the largest information and referral 
agency in the nation, 2-1-1 LA handles over 500,000 calls per year from individuals who are at greatest risk, yet have the fewest resources. Results from data analysis of screenings conducted between December 2011 and February 2012 showed that more than half of the children screened via phone interviews with families had a moderate to high risk of developmental delays [13]. Shockingly, more than one-fourth were identified as being at high risk for development delay/disability, indicating a need for further diagnostic evaluation and over twenty-percent of children screened were at high risk for autism spectrum disorder [13].

Clearly, these children in Los Angeles County who were at high-risk for developmental delays would likely have never been screened and referred without the innovative approach implemented by the 2-1-1 LA Project. Reaching families through technology, such as phone interviews, relies on families to take the first step; however, most families are not even aware that their children are at risk, and therefore are not likely to initiate screenings through this approach. Thus, the question asked by our researchers was, what other approaches might be utilized to reach the children in these hardest to reach communities?

This paper describes a mobile developmental screening project implemented to reduce the disparities in how families and their children living in low-income and diverse urban communities access developmental screening, and most importantly, early referral and early intervention [12]. To the best of our knowledge, the use of a mobile screening van is the first in the nation. Initial results from the screening project are reported. Finally, the paper concludes with a discussion about lessons learned, limitations, and recommendations for next steps.

\section{METHODS}

In order to increase the number of children who receive early developmental screening and access to the early intervention services to which they are entitled under the Individuals with Disabilities Education Improvement Act, 2004 (IDEA) [26], the Family Focus Resource Center (FFRC) Director and staff conceptualized the Mobile Developmental Screening Outreach Project. As the result of a generous grant of $\$ 50,000$ from the CVS Caremark Foundation, the FFRC acquired a custom designed and equipped van to conduct mobile outreach in underserved communities in Los Angeles County [27].
The FFRC is a parent-focused non-profit organization that is authorized to provide parent support, information, and referrals to families of children with developmental delays / disabilities. The FFRC is partially funded under Part D of IDEA [2004] in conjunction with state and private grants. The FFRC operates in partnership with the California State University, Northridge (CSUN) Michael D. Eisner College of Education and maintains strong partnerships with community agencies empowered with the responsibility to find and serve children with developmental needs. In California, the Department of Health and Human Development via Regional Centers is the lead agency responsible for child find and early intervention services for children younger than three years of age and the California Department of Education oversees implementation of IDEA for children from 3-21 years of age [26].

\section{Setting}

The Mobile Developmental Screening Outreach Project's van, painted with bright and cheerful graphics in both English and Spanish, went into hard to reach urban communities located in Los Angeles County with large numbers of low-income and / or culturally, ethnically, and linguistically diverse families [27]. The van participated in community events, such as child and family play days that typically attract a few hundred to a few thousand families of young children. The van was strategically placed near activities targeting very young children and an inviting play area was set-up consisting of a large grass like rug, an array of age appropriate toys and activities, and a canopy for shade.

The play area was available to all families and young children, regardless if they were interested in completing a developmental screening. Additionally, there was no limit as to how long children were welcome to stay and play. This served a two-fold purpose. First, we wanted families to feel welcome and free to participate without a sense of obligation to complete a developmental screener. Second, by not making the developmental screening a condition for their children being there, we would be more likely to attract a random sampling of families, versus families who were already concerned about their child's development.

Adjacent to the play area were two large folding tables and chairs. One of the tables displayed a variety of informational materials related to development and resources available to families in the community. The 
second table served as a place where families could sit and complete the developmental screener while their children played nearby under supervision by Early Childhood Education graduate students from CSUN. Once the parents completed the screener, they were invited to review results in the privacy of the comfortable seating area inside the van with one of the specially trained early childhood education graduate students and a supervisor.

\section{Participants}

In addition to the FFRC, there were three other primary partners: the Child Care Resource Center (CCRC), the North Los Angeles County Regional Center (NLACRC), and CSUN graduate students from the Early Childhood Education Master's degree program (ECEMA).

\section{Child Care Resource Center (CCRC)}

The CCRC is a local member of a network of 600 national, state, and county nonprofit agencies affiliated with Child Care Resource and Referral (CCR\&R). As one of the larger CCR\&R's in the United States, the CCRC provides programs, projects and services to 35,000 children and families each month and covers a geographical area of over 22,000 square miles that includes Los Angeles and San Bernardino Counties. Several times a year, the CCRC hosts events at a variety of public locations such as parks, which attract large numbers of families who have children younger than 5 years of age. Partnering with an agency such as CCRC, that has deep roots in the communities we wanted to reach, allowed the FFRC Mobile Developmental Screening Van to potentially reach large numbers of children at these events. Additionally, the CCRC served an important role in helping to advertise in advance to families, child care providers, and preschool programs that the van would be present at their events and what its purpose was.

\section{North Los Angeles County Regional Center (NLACRC)}

The NLACRC is a non-profit entity funded by the California Department of Developmental Services. It is the lead state agency responsible for finding, assessing, and purchasing services for children under 3 years of age who have, or are at risk for, developmental disabilities / delays under IDEA, Part C [26]. The FFRC developed a memorandum of understanding with the regional center so that families could be directly referred from the mobile van diagnosticians to the regional center for further diagnostic evaluation and referral for early intervention services when warranted. In accordance with IDEA, Part $B$, children over three years of age were referred to the local school district for assessment and early intervention services if appropriate.

\section{California State University, Northridge Early Childhood Education Master's Degree Students}

As part of a grant awarded by the Michael D. Eisner College of Education to increase partnerships in the community, faculty from the Department of Educational Psychology and Counseling, Early Childhood Education Masters in Arts Option (ECEMA) trained early childhood education master's level students to administer developmental screenings and to communicate with families using family-centered, culturally responsive interactions. Approximately $40 \%$ of ECEMA students were Hispanic and able to speak fluent Spanish, which proved to be a valuable contribution to the project as over $60 \%$ of the families involved in the screening project screened were Hispanic. As part of their required coursework, students participated in screening events, typically held on Saturdays, for which they earned course credit.

\section{Family and Child Participants}

The primary audience reached by the mobile developmental screening project was low-income families from culturally and ethnically diverse communities, in particular Spanish speaking families located in urban communities in Los Angeles County who frequently lack access to a medical home or appropriate and timely referrals [29]. Demographically (i.e., ethnicity, education, poverty level), the communities in which we conducted the screenings were comparable to Los Angeles County (Table 1).

\section{Instrumentation}

The Parents Evaluation of Developmental Status (PEDS) was selected for the project because it is recognized as being evidence-based, accurate, easy to use, and accessible to individuals from multiple languages with a range of educational levels [30]. Furthermore, the PEDS has been standardized with a population that represents the demographics of the U.S., and has a rating of $85 \%$ for sensitivity in its ability to accurately predict risk for developmental challenges [31]. The PEDS is designed for children from $0-8$ years of age and consists of 10 questions written at the $4^{\text {th }}-5^{\text {th }}$ grade reading level that can be completed by 
Table 1: Participant Community and Los Angeles County Socioeconomic Indicators

\begin{tabular}{|c|c|c|}
\hline & Participant's Community & Los Angeles County \\
\hline \multicolumn{3}{|l|}{ Ethnicity } \\
\hline White & 33.8 & 27.8 \\
\hline Black / African American & 6.8 & 8.3 \\
\hline Other race alone & 2.8 & 2.0 \\
\hline Two or more races & 0.3 & 0.3 \\
\hline \multicolumn{3}{|l|}{ Education } \\
\hline $9^{\text {th }}$ grade or less & 13.3 & 13.7 \\
\hline AA Degree & 7.6 & 6.8 \\
\hline Bachelor's Degree & 16.8 & 19.3 \\
\hline Professional or Graduate Degree & 7.1 & 10.2 \\
\hline Poverty level for families with children younger than 18 years of age & 18.7 & 19.8 \\
\hline
\end{tabular}

Source: Percent of Ethnicity, Education, and Poverty Level, 2008 - 2012 (American Community Survey); created on Healthy City.org, 12-10-15.

Table 2: Questions Asked on the PEDS Response Form

\begin{tabular}{|c|c|c|}
\hline Developmental & PEDS Questions & Age of Predictive Concern \\
\hline Global/Cognitive & $\begin{array}{c}\text { Do you have any concerns about your child's learning, development, } \\
\text { and behavior? }\end{array}$ & $0-8$ yrs. \\
\hline Expressive Language/Articulation & $\begin{array}{l}\text { Do you have any concerns about how your child talks and makes } \\
\text { speech sounds? }\end{array}$ & $0-8$ yrs. \\
\hline Receptive language & $\begin{array}{l}\text { Do you have any concerns about how your child understands what } \\
\text { you say? }\end{array}$ & 18 mos. - 8 yrs. \\
\hline Gross Motoe & $\begin{array}{l}\text { Do you have any concerns about how your child uses his or her } \\
\text { arms and legs. }\end{array}$ & 3-8 yrs. \\
\hline Behavior & Do you have any concerns about how your child behaves? & * \\
\hline School & $\begin{array}{c}\text { Do you have any concerns about how your child is learning } \\
\text { preschool or school skills? }\end{array}$ & $6-8$ yrs. \\
\hline Other/Health & Please list any other concerns. & $0-8$ yrs. \\
\hline
\end{tabular}

*Behavior and self-help are not scored as predictive concerns at any age, although the are considered when interpreting results.

Source: Brothers KB, Glascoe FP, Robershaw NS. PEDS: Developmental milestones: An accurate brief tool for surveillance and screening. Clin Pediatr 2008; 47 : 271-9.

parents in about $5-10$ minutes [31]. The PEDS questions are open-ended with the first question eliciting concerns in areas of global / cognitive functioning and the final question in other areas such as health issues. The remaining eight questions (relating to expressive / receptive language, fine / gross motor, social-emotional, behavioral, self-help and academic skills) are more specific and prompt parental 
responses of "no", "yes", or "a little" in addition to parents' verbatim descriptions of the nature of their concerns. When administered skillfully, the results from the PEDS are more likely to be coded and scored accurately, thus leading to appropriate referrals. Of particular relevance to this project, is that the PEDS has been normed in a variety of settings including health care, Head Start, and early childhood care / education programs making it appropriate for use in community-based settings. See Table 2 for an example of questions from the PEDS Response Form.

\section{Procedures}

The Mobile Developmental Screening Van participated in five community events throughout the Los Angeles County Area over a 6-month period of time. These events were organized by one of our partnering Agencies, were typically held on Saturdays in order to attract families of young children, and lasted for several hours. The van was stocked with PEDS protocols, informational materials, and children's activity coloring books in both English and Spanish. In addition to the FFRC staff and CSUN faculty who were present for the duration of all events, there were a minimum of four graduate students (English and Spanish speaking) who were scheduled for three-hour shifts in which they alternated between facilitating children's play near parents, administering the screening protocol, or discussing the results with families. The van was positioned near areas that would attract the largest possible numbers of families with young children and had a large designated area of age appropriate play materials and activities [27].

As parents approached the van, graduate students under the supervision of FFRC staff and CSUN faculty explained to families that we were there to provide free developmental screenings and invited them to complete a short questionnaire. Parents were provided with the PEDS Response Form and given the option of completing the PEDS independently or via interview by one of the trained graduate students. If parents were not interested, then we provided information on development and community resources. If parents agreed, then they were led to a private area where they completed and signed an informed consent form that included information about the child's age, gender, ethnicity, zip code, and prior educational history. The PEDS Scoring Guide suggests providing parents with limited reading skills an alternate way of completing the form without having to identify themselves as not being able to read [30]. Scoring of the PEDS followed the procedures outlined in the earlier section of this paper that describes the PEDS instrument. See Figure 1 for steps used to conduct the developmental screenings.

\section{RESULTS}

During the first phase of the Mobile Developmental Screening Outreach Project, we participated in five separate events located in geographically diverse

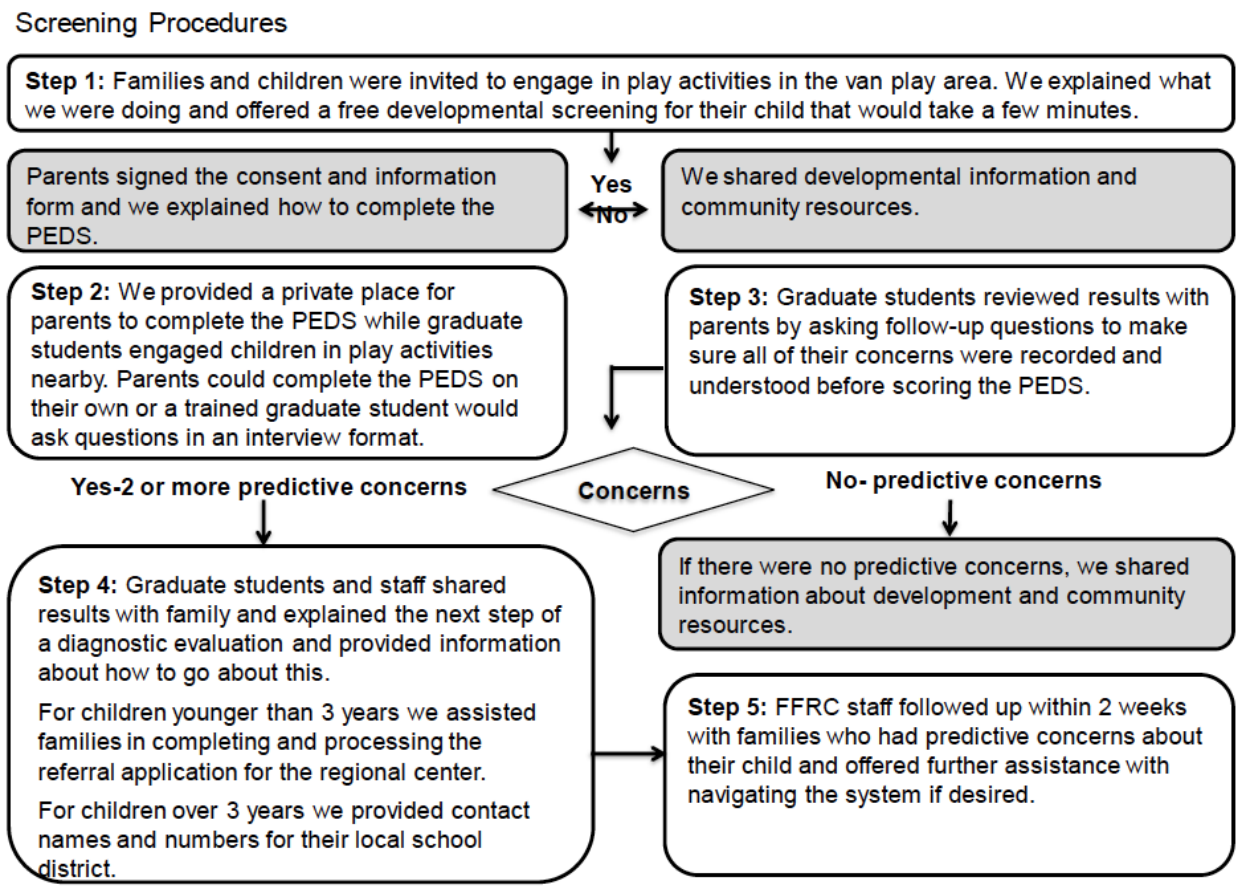

Figure 1: Flowchart shows the step-by-step process used for screening children. 
urban communities over the period of 6 months. Through these five events, the van project reached 94 families.

\section{Characteristics of Children Screened}

Children screened through the screening project ranged in age from 4 months to 6 years, and over $60 \%$ of children were between 18 months and 3 years of age. Though no formal information related to family income was collected, estimates from U.S. Census data for the communities represented in the study indicate that nearly $20 \%$ of families with children younger than 18 years of age live at the federal poverty level [28]. The number of children identified by parents as being Black / African American or Asian were comparable to the children living in the greater Los Angeles County. However, in stark contrast, the number of Hispanic children screened (61.7\%) was markedly higher and White children (7.4\%) were comparatively lower (Figure 2).

\section{Administering and Scoring the PEDS}

Scoring and interpretation of the PEDS results followed the procedures outlined in the PEDS Brief Guide to Scoring and Administration. After ensuring that parents' concerns were recorded accurately and verbatim, staff scored the results using the PEDS Scoring Form. Items marked as "yes" or "a little" were scored as either a predictive or non-predictive concern depending on the age of the child (See Table 2). Predictive concerns on the PEDS are those items with a high probability of moderate to high risk for developmental challenges at a specific age and were coded as predictive on the PEDS Scoring Form. Nonpredictive concerns on the other hand, represent items with a low probability of risk for the child's chronological age, and were scored accordingly; however, these concerns may need to be monitored over time [20]. For example, a parent may indicate concerns about receptive language development (e.g., understanding or listening); however, according to the PEDS this would not be interpreted as being a predictive concern until 18 months and older. See Table 2 for age at which an item is identified as a predictive concern.

According to the scoring algorithm recommended by the American Academy of Pediatrics, when parents indicate two or more predictive concerns about their children's development, they were referred for further diagnostic evaluation. Where parents indicate no predictive concerns, it was viewed as an opportunity to discuss normative developmental milestones and to provide parents with materials and information related to development.

The results from the Mobile Developmental Screening Outreach Project were categorized into three groups: parents with no concerns, parents with non-predictive concerns, and parents with predictive concerns. Because parents can report both predictive and non-predictable concerns for their child, there is overlap in how the results are reported. Of the 94 children screened, $27.6 \%$ of parents did not mark any items as being of concern.

Using the PEDS scoring algorithm as a guide, graduate students and staff assisted families with the

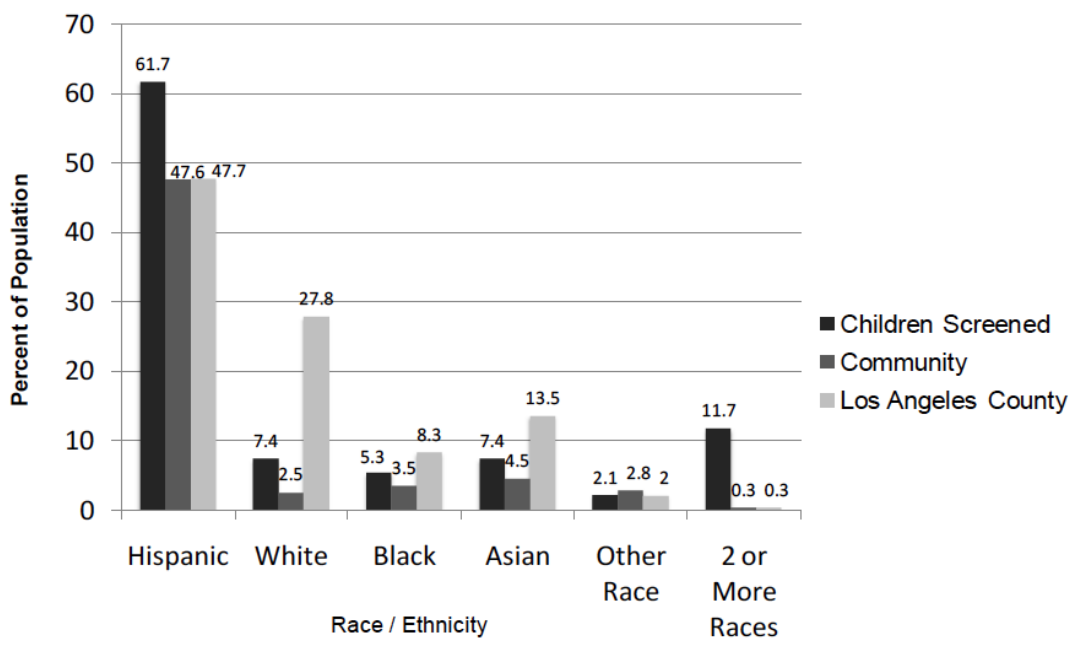

Figure 2: Race/Ethnicity of Children Screened.

Source: Percent of Race / Ethnicity of Participant's Screened, Participant's Community, Los Angeles County, 2008 -2012 (American Community Survey, 2008 - 2012); created on Healthy City.org, 12-10-15. 
next steps. Next steps could be as simple as answering parental questions and providing information about development or community resources for families who did not identify predictive concerns, to assisting with navigating the referral process for families whose children required further diagnostic evaluation.

\section{Non-Predictive Concerns}

Over $57 \%$ of parents reported that they had at least one non-predictive concern about their child's development, while $29.7 \%$ had two or more nonpredictive concerns. Even though Item 6 (Behavior) is not a predictive concern at any age and Item 7 (Social Skills) is not predictive after 5 months of age, both were the two items parents indicated most frequently as being of concern ( $46.8 \%$ and $25.5 \%$ respectively). Families of children who had non-predictive concerns were provided information about development and referrals to community based supports such as parenting classes or Early Head Start / Head Start.

\section{Predictive Concerns}

Surprisingly, a substantially high number of parents $(54.1 \%)$ reported one or more predictive concerns about their child's development, with $32.9 \%$ identifying two or more areas of development for which they were concerned. The two most frequently reported predictive concerns were Item 2 - speech / talking (35.1\%) and Item 3 - language / understanding (15.9\%), both of which are items strongly associated with high risk for developmental delay / disability. Whenever families identified two or more predictive areas of concern, the screening staff would sensitively discuss the next step of a more in-depth evaluation by a medical professional.

Of the 94 children screened, 14 (15\%) were referred to a regional center (children younger than 3 years) and $11(12 \%)$ to the local school district (children over 3 years) for further diagnostic evaluation. Staff informed parents about how and where they could have their child evaluated at no cost to them. For children younger than 3 years old, the FFRC staff discussed the referral process and offered to help parents complete a regional center referral application at that moment. A FFRC staff member would personally submit the completed and signed application directly to the regional center on the following business day and follow-up with families about the status of their referral. For children over 3 years of age, families were provided contact numbers for the local school district office responsible for services related to assessing for developmental delays / disabilities. FFRC staff followed up with families within two weeks to see if they had successfully made contact or if they needed any additional help.

\section{DISCUSSION}

The results from the Mobile Developmental Screening Outreach Project demonstrated that using a specially outfitted van can be an effective strategy for reaching the hardest to reach families in diverse and / or low-income communities. A much higher than expected percentage of children exhibited at least 1 predictive concern $(54 \%)$, while $32.9 \%$ had 2 or more concerns, indicating a need for referral for further diagnostic evaluation. Additionally, $30 \%$ of parents completing the PEDS had two or more non-predictive concerns, which indicated a need for monitoring or assessment. Similar to previous studies, our findings suggest that large numbers of children are not being screened in spite of the increase in prevalence of developmental learning challenges and the CDC/AAP recommendations for universal developmental surveillance and screening at all well-child visits $[10,11,13]$. Although medical professionals and state lead agencies for child find and intervention are largely responsible for identifying children early, it is evident that many children continue to fall through the cracks, and this is especially true for children from culturally and ethnically diverse communities $[9,14]$.

\section{LIMITATIONS}

Although our sample size was relatively small, families who participated did so from a place of inquiry about their child's developmental status, not in response to addressing a parent's already underlying concerns. Even though there was no randomization of participants, the relatively high number of children with moderate to high risk for developmental delay/disability is comparable to findings from other studies and warrants further investigation to determine if these same findings occur when the van is deployed on a larger scale. Similar to the findings of other screening initiatives, follow-up with families is a challenge, as many of the families in diverse and low-income communities are more transient and often reluctant to get involved with publicly funded programs $[11,13,15]$. Future implementation of the project will address this weakness by increasing the engagement of graduate students who can follow-up with families over a longer period of time to understand what happens after the screening and referral process. 


\section{NEXT STEPS}

Next steps for the Mobile Developmental Screening Outreach Project include identifying strategies to scale up the scope of the project to reach a larger number of children across a wider geographical area. Additionally, we are working toward leveraging existing partnerships and creating new ones with existing agencies, such as First 5 Best Start Communities, Resource and Referral Agencies, and Regional Centers. In order to increase the number of children screened, it would be beneficial to reach out to trained family childcare providers. These trained providers care for over $60 \%$ of children younger than three years of age who spend time outside of their parent's home. Early childhood educators can play an important role in early identification because they a) have knowledge of normative development, b) see children in day to day natural environments, and c) can assist parents in accessing diagnostic evaluations and services. One of the benefits of involving graduate students in the mobile outreach project is that they have the opportunity to engage in real world application of knowledge they have acquired in their coursework. Additionally, as more students become trained, they will be able to implement developmental screenings in their own early childhood education settings, thereby helping to make screening a routine practice, which is critical if we are to reach larger numbers of children before they enter kindergarten [32].

We know what to do for young children and we know how to do it. However public policy is slow in adapting the knowledge gained from neuroscience to allocate resources needed. The failure to address the needs of children who are at high risk has far reaching implications for children, families, communities, and society as a whole. Children are likely to experience an increased need for special education, diminished developmental outcomes, and increased heath concerns. Families will bear the burden of caring for children well into adulthood as a result of long-lasting developmental consequences. Furthermore, communities will need to allocate precious resources to provide supports and services for children throughout their lifespan. Ultimately, society will be impacted by both the costs for funding special education and lifelong support, but also by the loss of income that might have been earned if individuals were able to overcome their challenges.

Children of low socioeconomic families are especially at risk due to the compounded effects of poverty and lack of access to early identification and intervention. While we have a long way to go to ensure that all children have access to developmental screening, the Mobile Developmental Screening Van, as part of a larger comprehensive approach involving multiple community agencies, shows promise as an effective strategy to reach the families and children who are the hardest to reach, yet most in need of early screening, identification, referral, evaluation, and intervention.

\section{ACKNOWLEDGEMENTS}

The authors would like to acknowledge the generous contributions of others who share in the success of this project. First, thanks to our partner, the Child Care Resource Center, who made it possible for us to join their community events and to reach such a large number of children. Second, to the many staff members at the Family Focus Resource and Empowerment Center who worked behind the scenes to make sure that the van was always stocked with materials and ready to go. Thank you Stacey Melton Anderle for participating in the developmental screening events. Your example of professionalism, knowledge, and empathy provided a strong role model for the early childhood education graduate students. Special thanks to Victoria Berrey, MPH for her leadership in coordinating our participation in community events. We would also like to extend our thanks and appreciation to Kathy L. Scott, Ph.D., Administrative Analyst in the Center for Teaching and Learning for her tireless efforts editing and formatting this manuscript.

\section{REFERENCES}

[1] Shonkoff JP, Garner AS. The lifelong effects of early childhood adversity and toxic stress. Pediatrics 2012; 129: 232-46.

http://dx.doi.org/10.1542/peds.2011-2663

[2] Fox SE, Levitt $P$, Nelson CA. How the timing and quality of early experiences influence the development of brain architecture. Child Dev 2010; 81: 28-40. http://dx.doi.org/10.1111/j.1467-8624.2009.01380.x

[3] Shonkoff JP, Richter L, van der Gaag J, Bhutta ZA. An integrated scientific framework for child survival and early childhood development. Pediatrics 2012; 129: 460-72. http://dx.doi.org/10.1542/peds.2011-0366

[4] Johnson CP, Myers SM. Identification and evaluation of children with autism spectrum disorders. Pediatrics 2007; 120: 1183-215.

http://dx.doi.org/10.1542/peds.2007-2361

[5] Heckman J, Pinto R, Savelyev P. Understanding the mechanisms through which an influential early childhood program boosted adult outcomes. Am Econ Rev 2013; 103: 2051-86.

http://dx.doi.org/10.1257/aer.103.6.2052 
[6] Hyson M, Tomlinson HB. The early years matter: education, care, and the well-being of children, birth to 8 . New York: Teachers College Press 2014.

[7] Centers for Disease Control and Prevention. Prevalence of autism spectrum disorder among children aged 8 yearsautism and developmental disabilities monitoring network. Morb Mortal Wkly Rep Surveill Summ 2014; 63(2): 1-21.

[8] Radecki L, Sand-Loud N, O'Connor KG, Shapr S, Olson LM. Trends in the use of standardized tools for developmental screening in early childhood: 2002-2009. Pediatrics 2011; 128: $14-9$.

http://dx.doi.org/10.1542/peds.2010-2180

[9] King TM, Tandon SD, Macias MM, Healy JA, Duncan PM, Swigonski NL, Skipper SM, Lipkin PH. Implementing developmental screeing and referrals: lessons learned from a national project. Pediatrics 2010; 125(2): 350-60.

http://dx.doi.org/10.1542/peds.2009-0388

[10] Shattuck PT, Durkin M, Maenner M, Newschaffer C, Mandell DS, Wiggins $\mathrm{L}$, et al. The timing of identification among children with an autism spectrum disorder: findings from a population-based surveillance study. J Am Acad Child Adolesc Psychiatry 2009; 48(4): 474-82. http://dx.doi.org/10.1097/CHI.0b013e31819b3848

[11] Rosenberg SA, Robinson CC, Shaw EF, Ellison MC. Percent eligible versus served. Pediatrics 2013; 131: 38-46. http://dx.doi.org/10.1542/peds.2012-1662

[12] Bricker D, Macy M, Squires J, Marks K, Eds. Developmental screening in your community: an integrated approach for connecting children with services. Baltimore: Paul H. Brookes 2013.

[13] Roux AM, Herrera P, Wold CM, Dunkle MC, Glascoe FP, Shattuck PT. Developmental and autism screening through 2-1-1: reaching underserved families. Am J Prev Med 2012; 43(6 Suppl 5): S457-63.

[14] Mandell DS, Wiggins LD, Carpenter LA, Daniels J, DiGuiseppi C, Durkin MS, et al. Racial/ethnic disparities in the identification of children with autism spectrum disorders. Am J Public Health 2009; 99: 493-8.

http://dx.doi.org/10.2105/AJPH.2007.131243

[15] Lakes KD, Kettler RJ, Schmidt J, Fenney-Kettler K, Kamptner $\mathrm{L}$, Swanson J, et al. The CUIDAR early intervention parent training program for preschoolers at risk for behavioral disorders: an innovative practice for reducing disparities in access to service. J Early Interv 2009; 31: 167-78. http://dx.doi.org/10.1177/1053815109331861

[16] Maltese J, Aguayo J, Chavez J. A community-based response to Part C: A community embraces its most vulnerable children. Zero to Three 31(4): 17-23.

[17] lland ED, Weiner I, Murawski WW. Obstacles of Latina mothers of children with autism. Calif J Health Promot 2012; 10: 25-36.

[18] Barth RP, Scarborough A, Lloyd EC, Losby J, Casanueva C, Mann T. Developmental status and early intervention service needs of maltreated children [Internet]. U S Department of Health and Human Services, Office of the Assistant Secretary for Planning and Evaluation; 2007 [cited 2015 Nov 20]. Available from: http://aspe.hhs.gov/pdfreport/developmental-status-and-early-intervention-serviceneeds-maltreated-children
[19] National Scientific Council on the Developing Child. The science of early childhood development: closing the gap between what we know and what we do. Harvard University; 2007 [cited 2015 Nov 20]. Available from: http://developingchild.harvard.edu/resources/the-science-ofearly-childhood-development-closing-the-gap-between-whatwe-know-and-what-we-do/

[20] American Academy of Pediatrics. Policy statement: identifying infants and young children with developmental disorders in the medical home: an algorithm for developmental surveillance and screening. Pediatrics 2006; 118: 405-20.

http://dx.doi.org/10.1542/peds.2006-1231

[21] Marks KP, Glascoe FP, Macias MM. Enhancing the algorithm for developmental-behavioral surveillance and screening in children 0-5 years. Clin Pediatr 2011; 50: 853-68. http://dx.doi.org/10.1177/0009922811406263

[22] Jones MK, Laver L. Evidentiary review of screening infants for autism. Intellect Disabl Diagn J 3: 120-5.

[23] Schonwald A, Huntinton N, Chan E, Risko W, Bridgemohan C. Routine developmental screening implemented in urban primary care settings: more evidence of feasibility and effectiveness. Pediatrics 2009; 123: 660-8.

http://dx.doi.org/10.1542/peds.2007-2798

[24] Al-Qabandi M, Gorter JW, Rosenbaum P. Early autism detection: are we ready for routine screening? Pediatrics 2011; 128: e211-7. http://dx.doi.org/10.1542/peds.2010-1881

[25] Tout K, Halle T, Daily S, Albertson-Junkans L, Moodie M. The research base for a birth through age eight state policy framework. Washington DC: Child Trends 2013.

[26] Individuals with Disabilities Education Act, 20 U.S.C. $\S 1400$ 2004.

[27] Busillo-Aguayo J, Weiner I, Berrey V. Community based screenings: lessons learned. National Social Science Journal 2015; 45(1): 8-17.

[28] U S Census Bureau. American Community Survey 5-year data [Internet]. 2009-2013 [cited 2015 Dec 8]. U S Department of Commerce. Available from: https://www. census.gov/programs-surveys/acs/data.html

[29] Singh GK, Strickland BB, Ghandour RM, van Dyck PC Geographic disparities in access to the medical home among US CSHCN. Pediatrics 2008; 124: S352-60.

[30] Glascoe FP. Collaborating with parents: using parents evaluation of developmental status (PEDS) to detect and address developmental and behavioral problems. Nolensville (TN): PEDStest 2013.

[31] Brothers KB, Glascoe FP, Robershaw NS. PEDS: developmental milestones: an accurate brief tool for surveillance and screening. Clin Pediatr 2008; 47: 271-9. http://dx.doi.org/10.1177/0009922807309419

[32] Johnson-Staub J. Charting progress for babies in child care: promote access to early, regular, and comprehensive screening [Internet]. 2012 [cited 2015 Nov 20]. Available from: http://www.clasp.org/babiesinchildcare/ recommendations

Received on 15-12-2015

Accepted on 01-01-2016

Published on 15-01-2016

DOI: http://dx.doi.org/10.6000/2292-2598.2015.03.04.11

(c) 2015 Busillo-Aguayo et al.; Licensee Lifescience Global.

This is an open access article licensed under the terms of the Creative Commons Attribution Non-Commercial License (http://creativecommons.org/licenses/by-nc/3.0/) which permits unrestricted, non-commercial use, distribution and reproduction in any medium, provided the work is properly cited. 